DOI: $10.17805 /$ trudy.2019.1.7

\title{
СОВРЕМЕННЫЕ ПРОБЛЕМЫ УПРАВЛЕНИЯ НАУЧНО-ИССЛЕДОВАТЕЛЬСКИМИ ИНСТИТУТАМИ МИНИСТЕРСТВА ОБОРОНЫ РФ
}

\author{
А. В. Филонов \\ Московский гуманитарный университет
}

\begin{abstract}
Аннотация: В статье рассматриваются актуальные проблемы управления научно-исследовательскими институтами Министерства обороны РФ с точки зрения руководителя оперативного уровня.
\end{abstract}

Ключевые слова: научно-исследовательский институт; военно-промышленный комплекс; Министерство обороны

\section{CONTEMPORARY ISSUES OF MANAGEMENT IN RESEARCH INSTITUTES OF THE MINISTRY OF DEFENSE OF THE RUSSIAN FEDERATION}

\author{
A. V. Filonov
}

Moscow University for the Humanities

Abstract: The article discusses the current issues of management in research institutes of the Ministry of Defense of the Russian Federation from the point of view of the manager at the operational level.

Keywords: research institute; military-industrial complex; Ministry of Defense

Ныне складывающуюся военно-политическую, а вместе с тем и экономическую, обстановку в стране можно интерпретировать как «сложную». Она характеризуется нескончаемым потоком санкций, вводимых со стороны большинства западных стран, постепенным, но планомерным обострением отношений с ними, возобновлением гонки вооружений и т. д. Вместе с тем, возрастает и значение научно-исследовательских институтов сферы военно-промышленного комплекса (ВПК), являющихся основным «двигателем» разработки и развития новейших видов вооружения. И, несмотря на то, что их деятельность, в целом, можно признать успешной, существует ряд очевидных проблем.

Настоящая статья посвящена актуальным проблемам управления и способам их решения, характерных для оперативного уровня исследовательских институтов Министерства обороны (МО) РФ с точки зрения руководителя оперативного уровня. 
Итак, традиционно ВПК называется специфическое объединение производящих военную продукцию крупных государственных и частных предприятий, ассоциированных в своей деятельности с другими производителями военной продукции, научно-исследовательскими и испытательными организациями, заказывающими учреждениями вооруженных сил, государственно-административными органами управления (Хрусталев, 2002).

Касательно научно-исследовательских центров (НИЦ), они, в зависимости от формы собственности, могут быть:

- государственными;

- частными;

- смешанными.

Основными задачами государственных НИЦ, принадлежащих МО РФ, является проведение различных исследовательских работ в интересах МО РФ и разработка новых образцов вооружения и военной техники (ВиВТ).

Но ввиду широкого развития частного сектора ВПК, в последние годы наметилась явная тенденция на переориентацию формирования большего пакета заказов с государственных институтов на НИИ частной формы собственности, что является более затратным вариантом развития военной составляющей государства. В настоящий момент большинство НИИ МО РФ обеспечиваются лишь заказами на проведение исследовательских работ, не представляющих «особой ценности», в то время как НИИ частной формы собственности непрерывно обеспечиваются контрактами на разработку новых образцов ВиВТ. Виной сложившейся ситуации является статистика, согласно которой около 80\% заказов к государственным НИИ - проваливаются.

И, несмотря на предпринимаемые государством усилия по структурной оптимизации НИИ, проблемы, связанные с эффективностью их деятельности, остаются.

Основной причиной возникновения данной ситуации является их неконкурентоспособность, вызванная снижением научного потенциала. Высококвалифицированные кадры, положительно зарекомендовавшие себя работая в государственных НИЦ, спустя некоторое время принимают решения перейти в частные. Анализируя наметившуюся тенденцию, целесообразно выделить некоторые причины подобного поведения:

Первая причина - неконкурентоспособность оплаты труда.

По статистике, заработная плата в НИЦ частной формы собственности выгодно отличается. В среднем она более чем на 1/3 выше, чем в казенных НИИ на равнозначных должностях. В тоже время возникает вопрос, является ли указанная причина основополагающей, фундаментальной или относится к косвенным. 
Помимо неконкурентоспособности оплаты труда представляется возможным выделение еще, как минимум, трех проблем, оказывающих негативное влияние на эффективность деятельности государственных НИЦ.

Вторая причина - необоснованно «жесткий» регламент регулирования рабочего времени. Данная причина вытекает из ассоциированности данных структур с военным ведомством. Нарушение срочности выполнения государственного заказа влечет за собой достаточно крупные денежные штрафы. Данный фактор для многих руководителей является неким «психологическим барьером» к рационализму при принятии управленческих решений и «заставляет» их вводить необъяснимо жесткие ограничения в ходе планирования регламента рабочего времени, устанавливать серьезные взыскания за нарушение действующего регламента, а также осуществлять ежедневный контроль результатов работы. Меж тем, данные решения не только не способствуют повышению эффективности выполняемых задач, а наоборот, приводят к ее понижению.

Третья причина - «сложности» в отношениях с руководством. Данная причина, во многом, является следствием предыдущей. Трудности, связанные с необходимостью изменения утвержденного плана работ, периодичностью отчетности его выполнения, а также формой контроля деятельности ведут к значительным временным потерям и сказываются на объеме и качестве проделанной работы. Ситуацию усугубляет и существующий «кадровый голод», проявляющийся как в отсутствии необходимого количества персонала в целом, так и в недостатке высококвалифицированных специалистов, способных привнести новые идеи и подходы к выполнению поставленных задач в частности. Эти факторы приводит к возникновению социально-психологических конфликтов, что является существенным барьером на пути к достижению поставленных целей.

Четвертая причина - практическая невозможность следования графику выполнения задач. Данная причина, как и первая, на рассматриваемом уровне управления, не является решаемой полностью. Она является следствием видения высшим военно-политическим руководством страны необходимости развития тех или иных средств ВиВТ во времени в зависимости от меняющейся обстановки. А значит, любое затягивание процесса выполнения полученного заказа рискует стать причиной потери его актуальности, и, как следствие, прекращения финансирования. Данное состояние дел заставляет руководителей оперативного уровня прибегать к практике установления «строгих» временных рамок при планировании графика выполнения задач и «ужесточения контроля» их выполнения. Принимая во внимание особенности функционирования НИЦ, выбираемый руководите- 
Научные труды Московского гуманитарного университета 2019 № 2

лем оперативного уровня подход к решению существующей проблемы выходом не является.

Таким образом, проблема неконкурентоспособности уровня оплаты труда является весьма значимой, но не основной и далеко не единственной причиной сложившейся ситуации. Основной же причиной возникновения выявленных проблем является недостаточное внимание к ним со стороны руководителей оперативного уровня.

Ключевым шагом к изменению негативной тенденции является изменение подхода к ведению управленческой деятельности, переход к приоритетности целевой направленности, а не структурной принадлежности. Для повышения эффективности деятельности НИЦ МО РФ необходимо предпринять комплекс взаимосвязанных мер, направленных на оптимизацию подхода к оперативному планированию и контролю, а также на повышение имиджа организации. А именно:

Во-первых, расширение полномочий в выборе способа решения задач. В рассматриваемых организациях, как и в любых других, чья деятельность связана с научной и исследовательской составляющей, степень успешности решения задач во многом зависит от способности находить подход к ее решению, то есть творческой составляющей человеческого потенциала персонала инженерного звена. Поэтому, ограничение персонала в выборе вариантов решения задач является ошибочным, так как существенно снижает их оперативность.

Во-вторых, необходимо проведение оптимизации загрузки рабочего времени. Любые научно-исследовательские организации, как правило, являются проектно-ориентированными, то есть, конечной целью деятельности данных организаций является создание уникального продукта. Несмотря на тщательную проработку вопросов этапа планирования, количество внеплановых «внезапно возникающих» непосредственно в ходе создания продукта проблем, значительно. И, как правило, их решение является задачей персонала инженерного звена и требует большей свободы в выборе инструментария и более широких временных рамок. Поэтому, текущий подход к управлению, с применением всех видов контроля и, как правило, ежедневной формой отчетности, не оптимален.

И, наконец, в-третьих, необходима функциональная ереориентированность руководителей оперативного уровня управления, уход от контроля к содействию. Здесь, как и ранее, необходимо понимание особенности функционирования НИЦ, заключающейся в реализации «творческой составляющей» получаемых заказов непосредственно силами персонала инженерного звена. И, как показывает практика, вне зависимости от степени проработки вопросов этапа планирования, уровня организации, и даже показателя мо- 
тивации, количество текущих оперативных проблем, решение которых без «резолюции» непосредственного начальника невозможно, весьма высоко, т. е. уровень формализации оперативных процессов достаточно высок, что требует корректировки. Поэтому, пересмотр доминантной составляющей сути функциональной деятельности руководителей оперативного уровня, ее переход от контроля к обеспечению содействия - необходим.

Перечисленные меры в значительной степени улучшат внутренний климат в организации и являются необходимым шагом к повышению ее имиджа и конкурентоспособности, что позволит привлечь квалифицированные кадры необходимые для обеспечения конкурентоспособности организации.

\section{СПИСОК ЛИТЕРАТУРЫ}

Хрусталев, Е. Ю. (2002) Особенности функционирования и развития российского военно-промышленного комплекса // Менеджмент в России и за рубежом. № 2. С. 81-94.

Дата поступления: 15.03.3019 2.

Филонов Андрей Викторович - студент магистратуры направления «Государственное и муниципальное управление» Московского гуманитарного университета. Адрес: 111395, Россия, г. Москва, ул. Юности, д. 5. Тел.: +7 (499) 374-70-13. Эл. адрес: kafmen@mosgu.ru

Filonov Andrey Viktorovich, Graduate Student, programme of study "State and Municipal Administration", Moscow University for the Humanities. Postal address: 5, Yunosti St., Moscow, Russian Federation, 111395. Tel.: +7 (499) 37470-13. E-mail: kafmen@mosgu.ru

\section{Для цитирования:}

Филонов А. В. Современные проблемы управления научно-исследовательскими институтами Министерства обороны РФ [Электронный ресурс] // Научные труды Московского гуманитарного университета. 2019. № 2. URL: http://journals.mosgu.ru/trudy/ article/view/964 (дата обращения: дд.мм.гг.). DOI: 10.17805/trudy.2019.2.7 